\title{
CFD MODEL OF A SELF-AERATING FLOTATION CELL
}

\author{
P.T.L. KOH and M.P. SCHWARZ
}

\author{
CSIRO Minerals, Clayton, Victoria 3169, AUSTRALIA
}

\begin{abstract}
The effect of impeller speed on the air flow in a selfaerated Denver laboratory flotation cell was investigated using computational modelling. Air is induced into the slurry by the impeller's rotating action. The rate of air flow is determined by the suction pressure created by the impeller, the hydrostatic head of the slurry and the frictional losses along the delivery shaft from the inlet valve to the impeller. From two-phase simulations of the flotation cell at varying impeller speeds, the predicted air flow rates have been found to compare favourably against measured values reported in the literature. The effect of increasing impeller speed is to increase the air flow rate and gas holdup in the cell. Simulations with flotation kinetics showed that the gravitational force acting on the attached particles is significant. The effect is a decrease in the bubble rise velocity which in turn affects the flotation rate as predicted by the model.
\end{abstract}

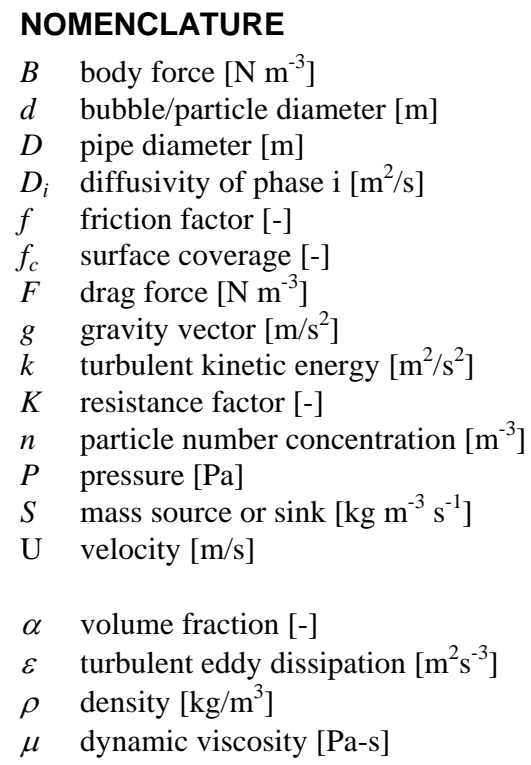

\section{INTRODUCTION}

Flotation is an important process in the minerals industry and most flotation is carried out using mechanically agitated cells ranging in volume up to $300 \mathrm{~m}^{3}$. Separation of the particles of valuable minerals from the ore is achieved when particles of the valuable minerals preferentially attach to air bubbles and are floated to the surface of the slurry via a froth layer. From the froth layer, the particles are removed by means of an overflow launder. The remainder of the slurry exits the cell through an outlet in the lower part of the cell. A class of the commonly used cells have air pumped into the slurry via a central shaft. The dispersion of air as fine bubbles for flotation is generated by a rotor-stator mechanism which also serves to mix the slurry and air bubbles. Various proprietary mechanisms are used in the minerals industry.

Self-aerating flotation cells, such as the Denver and WEMCO series, are also used in the minerals industry. In this case, air is induced into the slurry by the impeller's pumping action. The rate of air flow is controlled by the suction pressure created by the impeller, the hydrostatic head and the frictional losses along the delivery shaft from the inlet valve to the impeller. In this situation, the air flow rate is directly related to the impeller speed. A schematic diagram of the Denver cell is shown in Figure 1 .

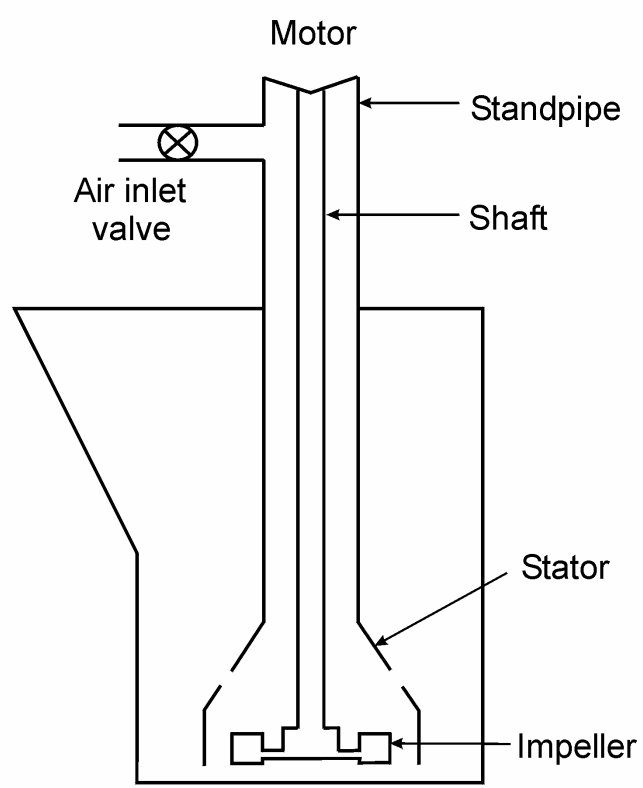

Figure 1: Schematic diagram of flotation cell.

Metallurgical performance is measured in terms of the recovery of the valuable mineral in the concentrate, the level of grade of the concentrate and the level of valuable mineral left in the tailings. Performance is affected by design features such as impeller and stator design, and tank geometry and internals. Flotation is also affected by operating variables such as slurry concentration, aeration rate and impeller speed. In self-aerating cells, the aeration rates and the impeller speeds are not independent.

The aeration behaviour of the Denver cell and several other self-aerating flotation machines has been extensively investigated by Arbiter and co-workers (1976), and by Harris and co-workers (1977) in both laboratory and fullsize machines. Some of the key findings with respect to induced air flow rates are summarised as follows. The induced air flow rate increases with impeller speed, it 
increases as pulp level is decreased, it increases as pulp density is reduced, and it decreases with frother addition. These dependencies are explained as follows: increasing impeller speed increases suction; decreasing pulp level and pulp density reduce back pressure near the impeller; and addition of frother decreases the size of the bubbles which then move away more slowly from the impeller and this build-up reduces fluid density and hence reduces power consumption.

For application in the chemical industry, there have been extensive investigations on gas-inducing impellers in agitated reactors (eg. Sawant et al., 1981; Joshi et al., 1982; Rielly et al, 1992; Forrester et al, 1994; Sardeing et al., 2006). Some of the reactors are in fact quite similar to Denver and Wemco machines. There is continuing interest in the search for new improved gas-inducing impellers for chemical processing.

CFD technology for the numerical modelling of complex unsteady, multi-phase flows typically found in agitated tanks of this type has developed to the point where it now has the potential to identify design and operational modifications to the process which can lead to process improvements. CSIRO Minerals has successfully applied CFD technology to mineral processes with complex unsteady multi-phase flows. For example, in the AMIRA P780A project, flotation cells up to $150 \mathrm{~m}^{3}$ from Outokumpu and Metso Minerals have been investigated to improve flotation performance (Koh et al., 2003a).

In the present paper, the effect of impeller speed on the air flow in a self-aerated Denver laboratory flotation cell was investigated using CFD modelling. The air flow rates predicted by CFD are compared against measured values reported in the literature for this cell (Girgin et al., 2006).

\section{MODEL DESCRIPTION}

The Denver flotation cell modelled here has a volume of 5.3 litres fitted with an eight-bladed impeller of diameter $72 \mathrm{~mm}$. The standpipe has a diameter of $42 \mathrm{~mm}$ and a rotating shaft of diameter $16 \mathrm{~mm}$. The cell is operated under semi-batch conditions (batch water, continuous air). The CFD mesh used for the flotation cell has 103,000 grid points as illustrated in Figure 2; a detailed mesh of the impeller zone is shown in Figure 3.

In the model, the multi-phase flow equations for the conservation of mass, momentum and turbulence quantities are solved using an Eulerian-Eulerian approach in which the phases are treated as interpenetrating continua. The multi-phase equations for unsteady flow can be written as follows (where $i=1$ for liquid, $i=2$ for gas):

$$
\begin{aligned}
& \frac{\partial\left(\alpha_{i} \rho_{i}\right)}{\partial t}+\nabla \cdot\left(\alpha_{i} \rho_{i} \vec{U}_{i}-\rho_{i} D_{i} \nabla \alpha_{i}\right)=S_{i} \\
& \begin{aligned}
\frac{\partial\left(\alpha_{i} \rho_{i} \vec{U}_{i}\right)}{\partial t}+ & \nabla \cdot\left(\alpha_{i} \rho_{i} \vec{U}_{i} \otimes \vec{U}_{i}\right) \\
& =\nabla \cdot\left(\alpha_{i}\left(\mu_{L, i}+\mu_{T, i}\right)\left(\nabla \vec{U}_{i}+\left(\nabla \vec{U}_{i}\right)^{T}\right)\right. \\
& -\alpha_{i}\left(B_{i}-\nabla P_{i}\right)+F_{i}+S_{i} \vec{U}_{i}
\end{aligned}
\end{aligned}
$$

The variables solved include velocity components $U_{i}$, pressure $P_{i}$ and volumetric fractions $\alpha_{i}$ for each of the phases. The mass source terms, $S_{i}$, include sources or sinks of gas entering and leaving the vessel. The inter-phase force $F_{i}$ is given by the standard drag force, while $B_{i}$ is the body force which includes the buoyancy force, and centrifugal and Coriolis forces in the rotating frame of reference. $\rho_{i}$ is the density, $\mu_{L, i}$ in the laminar viscosity and $D_{i}$ is the turbulent diffusivity.

The turbulent kinetic energy $k$ and turbulent dissipation rate $\varepsilon$ are for the continuous liquid phase. The turbulent viscosity $\mu_{T, i}$ in the liquid phase is calculated using the standard $k-\varepsilon$ turbulence model (Launder and Spalding, 1974).

The transport equations are solved using the computational fluid dynamics code CFX-4.4 (2001) and the multiple frames of reference technique has been used for modelling the impeller rotation in the stationary tank.

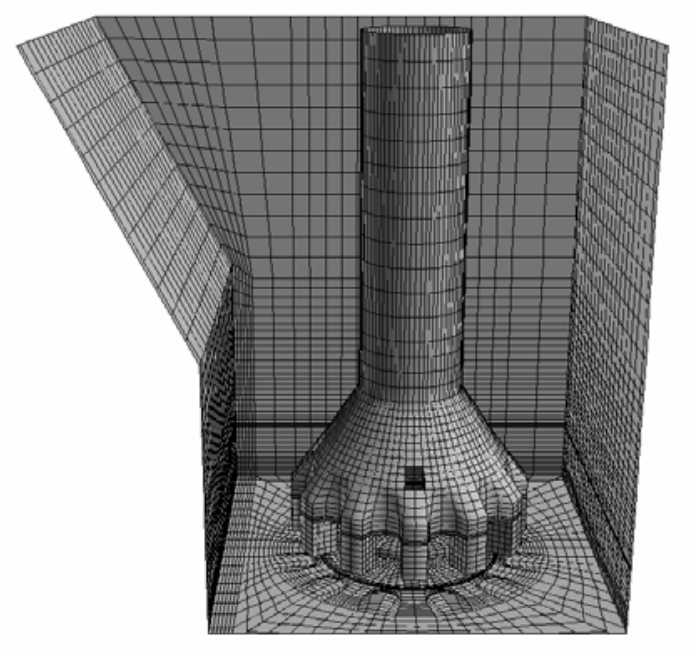

Figure 2: CFD mesh of flotation cell.

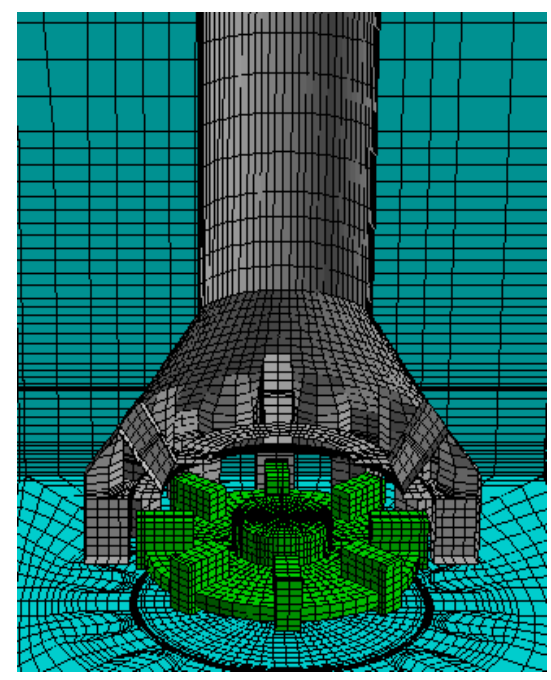

Figure 3: Detailed meshing of impeller.

The flow of air in the standpipe is not modelled. The inlet and outlet boundaries for the air flow are shown in Figure 4. A complete CFD model could include flow through the complex air valve drawing air from the atmosphere. An alternative approach which is used in this work involves using an overall pressure drop for delivering air from the atmosphere to the impeller. In this method, the total 
pressure drop is obtained by applying Fanning friction factor $(f)$ for air flow through the standpipe, together with another factor $(K)$ in equivalent length to diameter ratio to account for pipe roughness and pressure drop through the air valve and bends. These factors are included in the pressure drop equation as follows:

$$
\Delta P=2 f \rho_{g} V^{2}\left(\frac{L}{D_{e}}+K\right)
$$

where $\Delta P$ is the pressure drop, $\rho_{g}$ the air density, $V$ the mean flow velocity and $L$ pipe length. The equivalent pipe diameter $\left(D_{e}\right)$ is taken as four times the flow area divided by the wetted perimeter, $D_{e}=\left(D_{o}-D_{i}\right)$ where $D_{o}=26 \mathrm{~mm}$ and $D_{i}=16 \mathrm{~mm}$ respectively are the outer and inner diameters of the annular flow in the standpipe. The friction factor $f$ is calculated using the equation by Blasius which is expressed as a function of the pipe Reynolds number $(\mathrm{Re})$ as follows:

$$
\begin{gathered}
f=\frac{0.0791}{\operatorname{Re}^{0.25}} \\
\operatorname{Re}=\frac{D_{e} V \rho_{g}}{\mu}
\end{gathered}
$$

A pressure balance across the inlet boundary above the impeller shown in Figure 4 involving the suction pressure $(P)$ created by the impeller, the hydrostatic of the liquid and pressure drop of the air flow is given in the following equation:

$$
P=\rho_{l}\left(1-\alpha_{g}\right) g h+\Delta P+P_{O}
$$

where $P_{O}$ is the atmospheric pressure, $h$ the height of liquid above the inlet, $\rho_{l}$ the liquid density, $g$ the acceleration due to gravity, and $\alpha_{g}$ is the average gas holdup in the flotation cell.

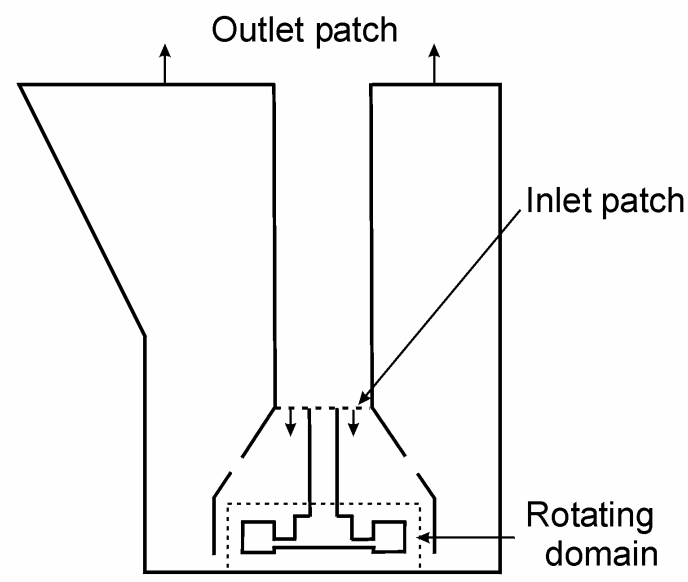

Figure 4: CFD setup of semi-batch flotation cell showing inlet and outlet boundaries for air.

In the model, the air flow rate as indicated by the velocity $(V)$ in Equation 3 is determined by iteration until the inlet pressure matches the suction pressure across the inlet boundary according to Equation 6 . The pressure across the inlet has to be averaged because it varies with radius due to the swirling motion. The air flow rate is adjusted between iterations if the pressure difference is greater than $10 \mathrm{~Pa}$ until a converged solution is obtained. The average pressure across the air inlet patch was observed to fluctuate between iterations as a result of changes to the air holdup in the cell. This fluctuation caused unstable air flow rate into the cell and a relaxation technique was implemented to minimise the fluctuation.

The froth layer is not included in the computational domain; only the pulp zone is simulated. At the froth-pulp interface, gas bubbles with attached particles are transferred from the pulp zone to the froth layer at the rate bubbles arrive at the interface. Based on bubble size measurements in air-water system with frother addition (Girgin et al., 2006), an average diameter of $1 \mathrm{~mm}$ is applied in the model.

For simulations with flotation kinetics, the transfer of particles between the pulp and bubbles is achieved by applying source terms for particle number concentration $n_{i}$ in the transport equation as follows:

$$
\frac{\partial\left(\alpha_{i} n_{i}\right)}{\partial t}+\nabla \cdot\left(\alpha_{i} n_{i} \vec{U}_{i}\right)=-\phi_{a}+\phi_{d}
$$

where $\phi_{a}$ and $\phi_{d}$ are sources or sinks specifying attachment and detachment rates respectively. The transient simulation uses variable time steps such that the mass error is less than $0.1 \%$ for each time step. The equations for collision frequency and attachment probability used in the model have been reported previously (Koh et al., 2000; 2003b; 2006).

\section{RESULTS}

Results of two-phase simulations have been obtained for the Denver cell at different impeller speeds, and typical mid-plane plots of the velocity vectors and void fraction at impeller speed of $1200 \mathrm{rpm}$ are shown in Figure 5 and Figure 6 respectively. CFD predictions indicate a complex flow field within the flotation cell and large fluid velocities observed in the impeller region.

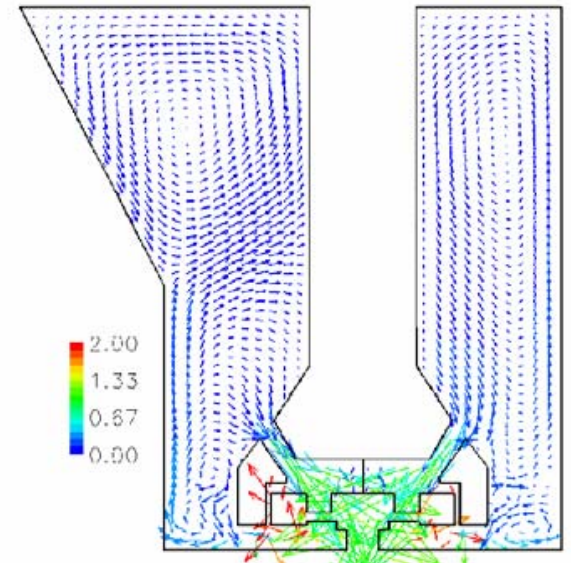

Figure 5: CFD predictions of velocity vectors $(\mathrm{m} / \mathrm{s})$ at impeller speed of $1200 \mathrm{rpm}$. 


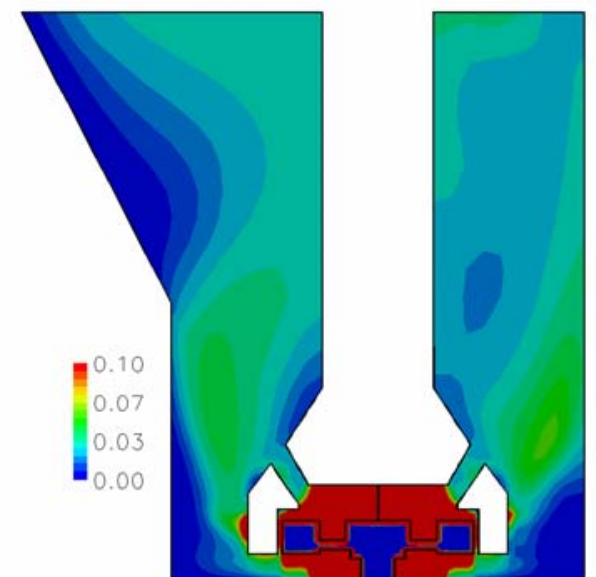

Figure 6: CFD predictions of void fraction at impeller speed of $1200 \mathrm{rpm}$.

\section{Comparing Air Flow}

From simulations in the air-water system at various impeller speeds, the predicted air flow rates have been obtained and are compared against literature values by Girgin and co-workers (2006). Based on the reported flow rate at $1800 \mathrm{rpm}$, a value for the factor $K$ of 342 was needed in the model to match the predicted and reported flow rates. Simulations at other impeller speeds have been performed using the same value of $K$. The air flow rates obtained by CFD at various impeller speeds are shown to compare favourably against measured data at frother concentrations of $20 \mathrm{ppm}$ and $50 \mathrm{ppm}$ in Figure 7. The differences in the measured air flow rates at the two frother concentrations are small and CFD results can be compared against either set of data. The effect of low frother addition is more evident in the measured air flow rates at high impeller speeds because of fewer larger bubbles in the impeller region.

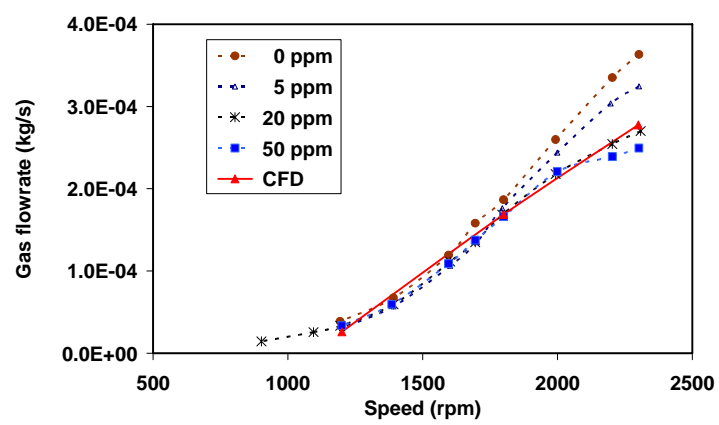

Figure 7: Comparison of CFD predictions against measured air flow rate at different frother concentrations plotted against impeller speed.

Besides increasing the air flow rate, increasing impeller speed also increases the suction pressure. Suction pressures of 1721, 2301 and 2965 Pa have been obtained at impeller speeds of 1200,1800 and $2300 \mathrm{rpm}$ respectively.

The bubble size measurements by Girgin and co-workers (2006) indicate that bubble size increases with increasing impeller speed in the Denver cell. This is in contrast to a forced air machine where an increase in impeller speed would produce more fine bubbles through the additional shear. The explanation is that in a self-aerated Denver cell the resulting increase in air flow rate with increasing impeller speed causes an increase in bubble size that more than offsets any effect of increasing shear. At this stage, bubble size modelling has not been performed and the flow is modelled for a bubble size of $1 \mathrm{~mm}$.

The other effect of increasing impeller speed is an increase in the gas holdup. With increasing impeller speed, the gas has a greater retention time in the cell because drag on the bubbles and pulp circulation both increase with increasing turbulence intensity. These effects are accounted for in the model.

\section{Flotation Kinetics}

Using the model previously reported by Koh and Schwarz (2006), simulations with flotation kinetics in the Denver cell have been performed with pulps of $10 \%$ by weight of monosized particles with a density of $2600 \mathrm{~kg} / \mathrm{m}^{3}$.

The gravitational force acting on particles attached to bubbles decreases the rise velocity of the aggregate especially with larger particles at higher loadings. The additional body force on the attached particles is incorporated in the present model by a source $\left(B_{p}\right)$ in the gas phase as follows:

$$
B_{p}=-4 f_{c}\left(\frac{d_{b}}{d_{p}}\right)^{2}\left(\rho_{p}-\rho_{l}\right) g n_{b}
$$

where $f_{c}$ is the fractional surface coverage, $n_{b}$ the local number concentration $\left(\mathrm{m}^{-3}\right)$ of bubbles, $\rho_{p}$ the density of particles, and $d_{b}$ and $d_{p}$ are the diameters of bubble and particles respectively. The effect of the particle diameter on both the rise velocity and the density of bubble-particle aggregates are illustrated in Figure 8 and Figure 9 where values have been calculated using a spreadsheet.

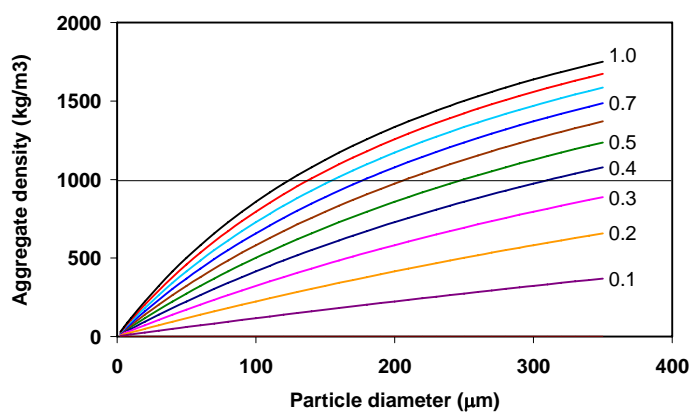

Figure 8: Aggregate density of a 1-mm bubble with fractional surface coverage of particles plotted against particle diameter.

The aggregate density increases with particle diameter because the total mass of attached particles and bubble increases more than the total volume of particles and bubble for larger particles. The aggregate rise velocity approaches zero for particles of $250 \mu \mathrm{m}$ size with a surface coverage of 0.5 and an effective density close to that of water as shown in Figure 8. The rise velocity at various loadings in Figure 9 is obtained for bubbles in a quiescent fluid. One can expect a similar effect in turbulent flow where the bubble rise velocity is reduced by the attached particles. The bubble-particle aggregates can sink if the particles are large and the bubble load also is high. 


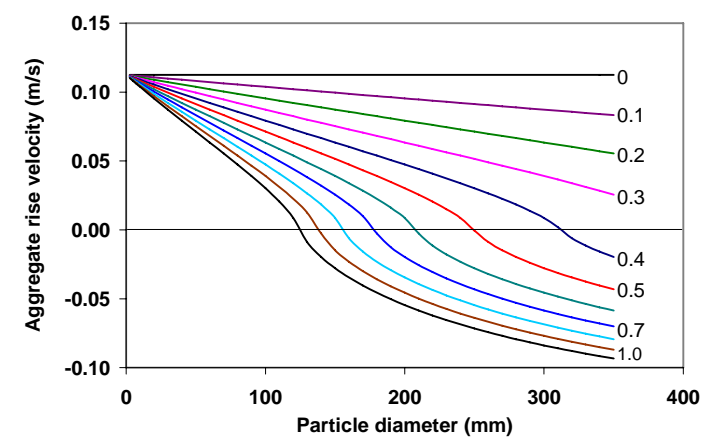

Figure 9: Rise velocity of bubble-particle aggregate with fractional surface coverage on a 1-mm bubble plotted against particle diameter.

From CFD simulations with flotation in the Denver cell, the total number of particles remaining in the cell is determined by summing particles in all the finite volumes. The results for different particle diameters are shown in Figure 10 where the sum of free and attached particles remaining in the cell operating at $1200 \mathrm{rpm}$ is plotted as a function of time. The rate constants are obtained from this diagram assuming first order kinetics and plotted against particle diameter in Figure 11.

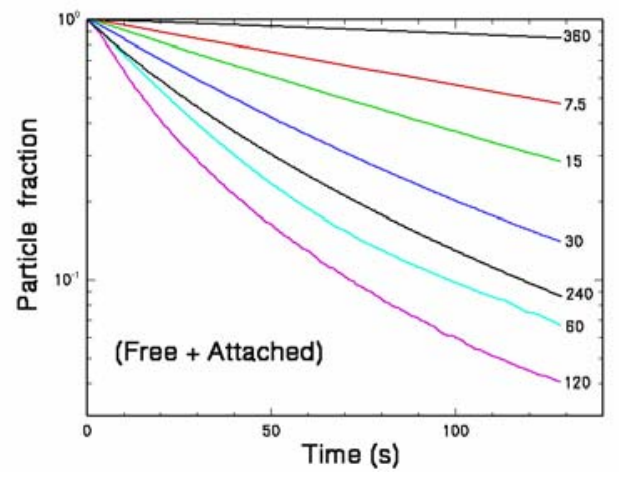

Figure 10: CFD prediction of the fraction of free and attached particles remaining in the cell plotted against time for different particle diameters $(\mu \mathrm{m})$.

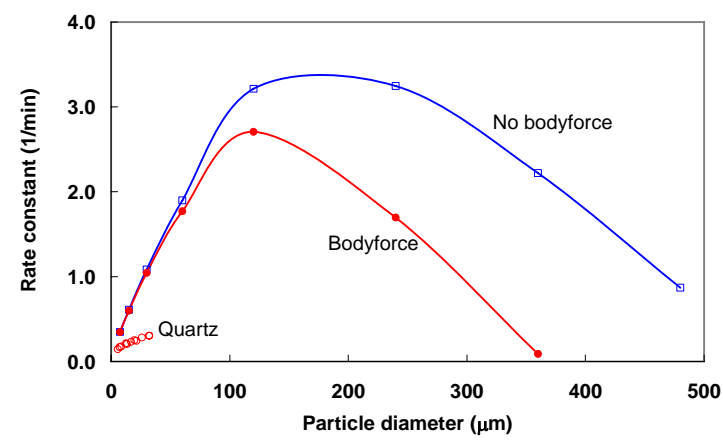

Figure 11: CFD predictions of rate constant plotted against particle diameter and the effect of body force on the attached particles. Comparison with literature data.

The effect of incorporating Equation 8 into the model is to decrease the flotation rate as shown in Figure 11 where flotation rates with and without body force at different particle sizes are compared. The effect is greater at larger size as expected. In the previous model (Koh and Schwarz, 2006) where the effect of the body force due to gravity of the attached particles was not included, the flotation rates for larger particles were higher. The smaller rise velocity with body force confirms indirectly that transport rate through the flotation cell to reach the frothpulp interface is an important contributor to the overall flotation rates.

In the present simulations, the maximum loading on a bubble has been assumed to be equal to a half mono-layer coverage $\left(f_{c}=0.5\right)$ in the absence of experimental data. Flotation rates of quartz particles in a Rushton-turbine stirred tank reported in the literature (Ahmed and Jameson, 1985) are also plotted in Figure 11 for comparison. The CFD predicted rates are higher because power consumption is greater in the Denver cell (impeller speed $1200 \mathrm{rpm}$ ) than in the stirred tank (impeller speed $600 \mathrm{rpm})$. Besides, there is no froth in the model: the reported rates include recovery through the froth layer and would therefore be lower than the predicted rates which account only for flotation to the pulp-froth interface. It is possible that detachment rates in the model may be too low. With higher rates of detachment, the maximum flotation rate constant could occur at less than 100 microns as normally observed in flotation tests. Work on this aspect of the model is still in progress.

The distributions of net attachment rates in the Denver cell operating at $1200 \mathrm{rpm}$ after a flotation time of $129 \mathrm{~s}$ for three particle species of diameters 15, 60 and $120 \mu \mathrm{m}$ are plotted in Figures 12 to 14 . The negative values represent detachment. For small particles of $15 \mu \mathrm{m}$, the attachment rates are highest near the impeller tip and in regions of highest shear. There is little detachment for $15 \mu \mathrm{m}$ particles. For larger particles of 60 and $120 \mu \mathrm{m}$, the locations of highest attachment rates are away from the impeller. In fact, for $120 \mu \mathrm{m}$ particles, the highest rates are outside the shroud. The high detachment rates for 60 $\mu \mathrm{m}$ particles are near the impeller tip, while the high detachment rates for $120 \mu \mathrm{m}$ particles are around the impeller and outside the shroud.

The results indicate that the smaller particles need higher impeller speeds for flotation while larger particles float best at lower speeds. Thus, flotation cells with an assigned impeller speed for a particular particle size should perform best for that size. This agrees with practice in many mineral plants where the feed streams are sized into coarse, fines and slimes and treated in customised flotation cells where the speeds are adjusted to suit the particle size.

\section{CONCLUSION}

The hydrodynamics and flotation kinetics in the Denver laboratory cell have been studied using CFD modelling. From two-phase simulations at different impeller speeds, the predicted air flow rates have been found to compare favourably against measured values reported in the literature. The model provided detailed hydrodynamics of the Denver cell that are very useful for understanding batch flotation test results and for investigations in the design and operation of larger flotation cells. 


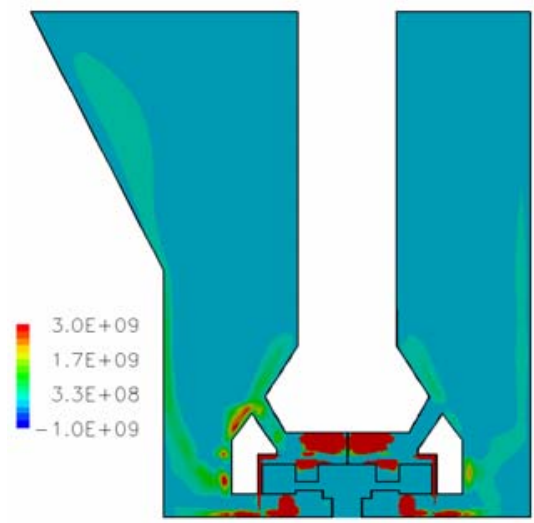

Figure 12: CFD predicted net attachment rates $\left(\mathrm{m}^{-3} \mathrm{~s}^{-1}\right)$ after flotation time of $129 \mathrm{~s}$ for particles of $15 \mu \mathrm{m}$ diameter in the stirred cell. Negative values indicate net detachment.

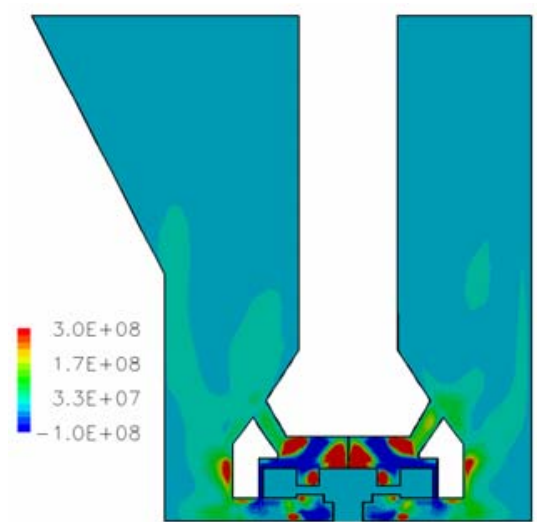

Figure 13: CFD predicted net attachment rates $\left(\mathrm{m}^{-3} \mathrm{~s}^{-1}\right)$ after flotation time of $129 \mathrm{~s}$ for particles of $60 \mu \mathrm{m}$ diameter in the stirred cell. Negative values indicate net detachment.

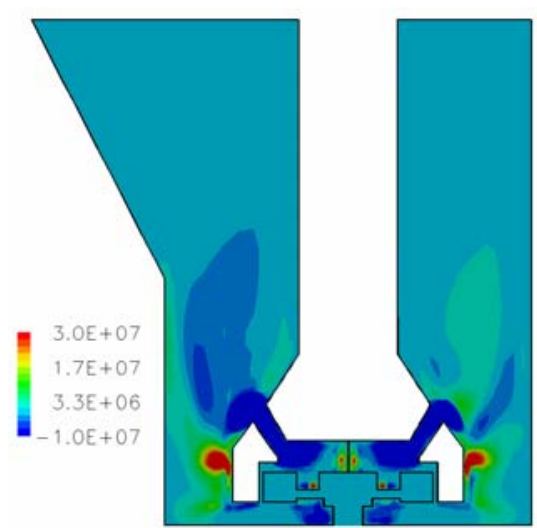

Figure 14: CFD predicted net attachment rates $\left(\mathrm{m}^{-3} \mathrm{~s}^{-1}\right)$ after flotation time of $129 \mathrm{~s}$ for particles of $120 \mu \mathrm{m}$ diameter in the stirred cell. Negative values indicate net detachment.

\section{REFERENCES}

AHMED, N. and JAMESON, G.J., (1985), "The effect of bubble size on the rate of flotation of fine particles", International Journal of Mineral Processing, 14, 195-215.
ARBITER, N., HARRIS, C.C. and YAP, R.F., (1976), "The air flow number in flotation machine scale-up", International Journal of Mineral Processing, 3, 257-280.

CFX USER GUIDE, RELEASE 4.4, (2001) Computational Fluid Dynamics Services, AEA Industrial Technology, Harwell Laboratory, Oxfordshire, UK.

FORRESTER, S.E. and RIELLY, C.D., (1994), "Modelling the increased gas capacity of self-inducing impellers", Chemical Engineering Science, 49, 57095718.

GIRGIN, E.H., DO, S., GOMEZ, C.O. and FINCH, J.A., (2006), "Bubble size as a function of impeller speed in a self-aeration laboratory flotation cell”, Minerals Engineering, 19, 201-203.

HARRIS, C.C. and MENSAH-BINEY, R.K., (1977), "Aeration characteristics of laboratory flotation machine impellers”, International Journal of Mineral Processing, 4, 51-67.

JOSHI, J.B., PANDIT, A.B. and SHARMA, M.M., (1982), "Mechanically agitated gas-liquid reactors", Chemical Engineering Science, 37, 813-844.

KOH, P.T.L., MANICKAM M. and SCHWARZ M.P. (2000), "CFD simulation of bubble-particle collisions in mineral flotation cells", Minerals Engineering, 13, 14551463.

KOH, P.T.L., SCHWARZ, M.P., ZHU, Y., BOURKE, P., PEAKER, R. and FRANZIDIS, J.P., (2003a), "Development of CFD models of mineral flotation cells", Third International Conference on Computational Fluid Dynamics in the Minerals and Process Industries, Melbourne, Australia, December, p. 171-175.

$\mathrm{KOH}$, P.T.L. and SCHWARZ M.P. (2003b), "CFD modelling of bubble-particle collision rates and efficiencies in a flotation cell”, Minerals Engineering, 16, 1055-1059.

KOH, P.T.L. and SCHWARZ, M.P., (2006), “CFD modelling of bubble-particle attachments in flotation cells”, Minerals Engineering, 19, 619-626.

LAUNDER, B.E. and SPALDING, D.B., (1974) "The numerical computation of turbulent flows", Comp. Meths. Appl. Mech. Engng., 3, 269-289.

RIELLY, C.D., EVANS, G.M., DAVIDSON, J.F. and CARPENTER, K.J., (1992), "Effect of vessel scaleup on the hydrodynamics of a self-aerating concave blade impeller”, Chemical Engineering Science, 47, 3395-3402.

SARDEING, R.F., POUX, M. and XUEREB, C., (2006), "Development of a new gas-inducing turbine family: The partially shrouded turbine”, Ind. Eng. Chem. Res., 45, 4791-4804.

SAWANT, S.B., JOSHI, J.B., PANGARKAR, V.G. and MHASKAR, R.D., (1981), "Mass transfer and hydrodynamic characteristics of the Denver type of flotation cells", The Chemical Engineering Journal, 21, 11-19. 